\title{
Estudo Correlacional entre Escala de Aconselhamento Profissional (EAP) e Self-Directed Search (SDS)
}

\author{
Ana Paula Porto Noronha \\ Rodolfo Augusto Matteo Ambiel \\ Universidade São Francisco
}

\begin{abstract}
RESUMO
A importância das pesquisas que visam desenvolver, validar e adaptar instrumentos de avaliação psicológica se dá no sentido de oferecer condições apropriadas de trabalho aos profissionais da Psicologia, especialmente no domínio da Orientação Profissional, no qual os instrumentos psicológicos visam levantar as características, interesses e habilidades do sujeito, a fim de se promover reflexão e tomada de decisão consciente e adequada. Nesse estudo, buscou-se a correlação entre os itens da Escala de Aconselhamento Profissional (EAP) com os itens da escala Atividades do Self-Directed Search (SDS) em uma amostra formada por estudantes de Psicologia, Educação Artística e Veterinária. Percebeu-se que a Tipologia de Holland pode ser uma ferramenta importante para predizer as atividades profissionais dos estudantes em suas especialidades, e que a EAP parece ser um bom instrumento para avaliar os interesses por meio das atividades profissionais, embora necessite ainda de mais estudos.
\end{abstract}

Palavras-chave: testes psicológicos; orientação profissional; avaliação psicológica.

\section{ABSTRACT \\ Correlational Study Between Escala de Aconselhamento Profissional (EAP) and Self-Directed Search (SDS)}

The importance of research intended to develop, validate and adjust psychological assessment instruments relies on offering appropriated work conditions to professionals in Psychology, specially in Professional Counseling domain wherein psychological instruments aim to identify subject's characteristics, interests and abilities, promote reflection and consciously fit decisions. In this study, correlations between items of the Escala de Aconselhamento Profissional (EAP) and items of the Self-Directed Search (SDS) Activities Scale were examined, in a sample composed by Psychology, Arts and Veterinary students. It was observed that the Holland Typology may be considered an important tool to predict students' professional activities in their areas, and also, that the EAP appears to be a good instrument to assess interests through professional activities, although further studies are necessary.

Keywords: psychological tests; professional counseling; psychological assessment.

A necessidade de pesquisas que visem o desenvolvimento, a validação e adaptação de testes psicológicos voltados para a Orientação Profissional (OP) fica evidente uma vez que se entende que os últimos têm o objetivo de levantar as características pessoais do orientando, a fim de promover reflexão e autoconhecimento acerca das próprias características e habilidades. Ainda, ao considerar que os instrumentos de avaliação psicológica são ferramentas de uso exclusivo dos profissionais de Psicologia, devem ser usados com cautela e adequação. Contudo, uma grande parcela da população profissional acredita que os instrumentos não são necessários ou que são menos importantes.
Essa crença se justifica de certa forma pela história de utilização dos instrumentos em décadas passadas no Brasil, que se dava de forma inadequada e equivocada, sem pesquisas atestando a qualidade psicométrica desses instrumentos e sem estudos de adaptação à realidade brasileira. Atualmente, esta situação já não é tão freqüente, uma vez que medidas tomadas pelo Conselho Federal de Psicologia (CFP, 2001, 2003) demandaram e propiciaram um crescente aumento no número e na qualidade dos estudos científicos acerca dos instrumentos disponíveis no Brasil, instituindo a obrigatoriedade da exposição da fundamentação teórica do construto; ao menos um estudo com evidências 
empíricas de validade e precisão das interpretações e escores apresentados no teste; além de apresentação de sistema de correção e interpretação dos resultados. Nessa direção, está prevista a falta ética para aqueles que usarem instrumentos que não constem da relação de teste aprovados, divulgada pelos meios de comunicação do CFP.

No contexto da OP, um dos construtos que tem merecido destaque é o de interesse, e no que respeita ao seu conceito, Leitão e Miguel (2004) afirmam que existem diversas teorias que tratam desse assunto, embora ainda haja discussão a respeito de sua conceituação. Savickas (1995) considera que as teorias podem ser divididas em três categorias. Na primeira, o autor aloca as teorias da aprendizagem, que afirmam que o indivíduo aprende a se interessar por atividades que executa de maneira satisfatória. Savickas cita Fryer (1931) como o precursor desta escola, na qual os interesses eram definidos como aceitação ou rejeição de estímulos ambientais. Strong (1943), por sua vez, avançou com relação à Fryers ao afirmar que os interesses são fruto da recognição de habilidades bemsucedidas, passando assim a integrar uma esfera motivacional.

A primeira categoria é finalizada com a Teoria Sócio-Cognitiva de Desenvolvimento de Carreira (TSCDC), proposta por Lent, Hackett e Brown (1994). Essa teoria, considerada a mais contemporânea, focase na auto-eficácia e nas expectativas de resultado como antecedentes dos interesses, enfatizando que a história de reforçamento desde a infância leva a pessoa a desenvolver um senso de eficácia e expectativas positivas com relação a determinadas atividades.

A segunda categoria postulada por Savickas (1995) diz respeito às teorias da personalidade. Nessa concepção, os interesses teriam um papel de extensão das necessidades do indivíduo e de expressão de seu autoconceito em termos ocupacionais. Assim, a partir das respostas do indivíduo aos inventários de interesse seria possível conjecturar sobre sua personalidade de modo indireto.

A terceira e última categoria dá ênfase aos papéis sociais, considerando que ao aceitar um determinado papel, o indivíduo consente com padrões de preferência inerentes a ele. Tais padrões estariam socialmente condicionados à raça, à idade, ao sexo e à classe econômica.

Em síntese, Savickas (1995) alerta que os psicólogos que trabalham nesse âmbito não devem isolar o construto de outras variáveis, principalmente da per- sonalidade e estilo de vida. Buscando o significado na etimologia do termo, o autor conclui que os interesses assumem um papel motivacional de intermediação do sujeito com o mundo e, uma vez identificando-os como construtos motivacionais, teriam como subjacentes as necessidades e os valores. Assim, o interesse seria a atração por algo externo que tem o potencial de trazer benefício ao indivíduo, constituindo uma relação com o ambiente.

Em outras palavras, evocando a primeira categoria distinguida pelo autor, o sujeito é atraído, ou seja, prefere determinada atividade para a qual ele julga ter habilidade e da qual espera bons resultados para si. Dessa forma, Savickas (1995) aponta que os autores de inventários de interesse, baseados na perspectiva da ciência moderna, qualificam o construto como padrões de preferência, oposição ou indiferença a determinados estímulos ambientais. Anastasi e Urbina (2000) vão na mesma direção, e afirmam que os interesses são tendências para reagir favoravelmente ou não a determinada classe de estímulos, indicando consistência ou inconsistência de resposta.

Nesse sentido, Noronha, Sisto e Santos (2007), ao construírem a Escala de Aconselhamento Profissional (EAP), adotaram concepção teórica semelhante. No manual técnico, os autores afirmam que a concepção que subjaz é de que o interesse profissional é a preferência por algumas atividades laborais, compreendendo que uma pessoa pode ter interesse por atividades em áreas diferentes da que ele escolheu como carreira.

Buscando obter evidências empíricas de qualidade psicométrica para a EAP, os autores realizaram estudo utilizando a Escala de Aconselhamento Profissional (EAP), no qual participaram 762 estudantes universitários de 13 carreiras distintas, sendo a maioria do Estado de São Paulo. Nesse trabalho, os autores investigaram as evidências de validade de construto e, por meio de uma análise fatorial, chegaram a uma solução composta por sete fatores, a saber: Ciências Exatas, Artes e Comunicação, Ciências Biológicas e da Saúde, Ciências Agrárias e Ambientais, Atividades Burocráticas, Ciências Humanas e Sociais Aplicadas e Entretenimento, cujos índices de saturação foram superiores a 0,30 e a variância explicada de 57,31\%.

A validade de critério também foi considerada, uma vez que foram realizadas análises que buscaram traçar o perfil das carreiras participantes, por meio da avaliação da intensidade das preferência por atividades típicas de suas áreas. Para tanto, foram comparadas as médias obtidas pelos participantes em cada 
dimensão em relação à sua carreira, e percebeu-se que algumas atividades, embora não façam parte do repertório típico de determinada profissão, podem constituir-se como altamente preferidas pelos sujeitos. Quanto à precisão, estudos de consistência interna foram realizados, sendo que os valores de alfa de Cronbach para os fatores ficaram entre 0,79 e $0,94 \mathrm{e}$ os de Spearman-Brown e Guttman entre 0,75-0,91.

O presente estudo também abordará outro instrumento, cuja abordagem é a apresentada por Holland, Frietsche e Powell (1994). Os autores concebem que os interesses poderiam ser formados ou atualizados durante toda a vida, dependendo dos ambientes nos quais a pessoa conviva, afirmando que forças culturais e pessoais moldam o indivíduo de diferentes formas. A partir dessas experiências, aprende-se a preferir determinadas tarefas em detrimento de outras. Ao longo do tempo, essa preferência se torna um forte interesse, que levará ao desenvolvimento de competências, que por sua vez, criarão uma disposição a pensar, perceber e agir de maneiras especiais.

Dentre as várias concepções sobre os interesses profissionais, destaque também deve ser dado à de Holland e Powell (1994), estudada e replicada em vários países com resultados que corroboraram seus achados. Essa teoria, a partir da qual foi desenvolvido o Self-Directed Search (SDS), consiste numa tipologia, organizada graficamente de forma hexagonal, que indica a semelhança da pessoa com um dos seis tipos de personalidade e ambiente. Nesse sentido, os autores, ao justificarem sua teoria tipológica, afirmam que a escolha profissional é uma expressão da personalidade, e esta, por sua vez, é o resultado de um processo de interações e experiências do indivíduo com seu ambiente.

Os tipos, denominados Realista, Investigativo, Artístico, Social, Empreendedor e Convencional (RIASEC), apresentam maior ou menor correlação entre si de acordo com a distância que eles mantêm quanto à posição no hexágono. Assim sendo, os tipos têm características próprias de personalidade e de ambientes (Osborn, 2002). O tipo Realista geralmente refere-se ao sujeito pouco sociável, com boa coordenação motora, força física, rapidez, com preferência por problemas concretos aos abstratos e que se vê como agressivo e varonil, com valores políticos e econômicos definidos. O indivíduo do tipo Investigativo tende a ser hábil em lidar com palavras e idéias, sendo analítico e crítico, e sentindo o permanente desejo de entender as coisas. Já o tipo Artístico é sentimental, mais emocional que racional e utiliza muito de sua intuição e imaginação na resolução de problemas cotidianos (Mansão, 2005).

As pessoas do tipo Social preferem atividades que envolvam interações com outras pessoas, e evitam trabalhar com máquinas ou ferramentas, além de valorizar questões éticas envolvidas no contato social. $\mathrm{O}$ tipo Empreendedor abrange aqueles interessados em interações interpessoais, que visem objetivos organizacionais e políticos ou ganhos econômicos. Finalizando, o tipo Convencional refere-se às pessoas que gostam de manipular e analisar dados e números, conferindo muita importância para o econômico e pouca para o ético e religioso, preferindo atividades sistemáticas, organizadas e passivas (Mansão, 2005; Conn \& Rieke 1994; Osborn, 2002).

No Brasil, Mansão (2005) realizou o estudo de adaptação do SDS ao contexto nacional. Sua amostra foi composta por 1162 (53,4\% de mulheres) estudantes de Ensino Médio de dois colégios públicos e um particular de uma cidade do interior de São Paulo. Com relação à validade, buscou-se evidências por meio de uma análise fatorial que indicou que a teoria de Holland pode ser aplicada à população brasileira, pois os fatores configuraram-se de acordo com o modelo hexagonal. Ainda no que toca aos estudos de validade, o SDS foi correlacionado a outros três instrumentos de avaliação dos interesses, a saber, o LIP Levantamento de Interesses Profissionais, Inventário de Interesses de Angelini e o QVI - Questionário Vocacional de Interesses. Com os três instrumentos foram encontradas correlações significativas.

Em acréscimo, o SDS foi aplicado juntamente com o BPR-5 - Bateria de Provas de Raciocínio, e os achados revelaram apenas duas correlações significativas entre habilidades e tipologias, porém com valores considerados baixos, apontando para a validade discriminante do SDS. Com relação à precisão, foi realizada análise da consistência interna para cada uma das tipologias propostas pelo modelo RIASEC, variando entre 0,87 e 0,90 , e pelos coeficientes de teste re-teste, que, por sua vez, estiveram entre 0,82 e 0,91.

Anteriormente Primi, Moggi e Casellato (2004) já haviam estudado o SDS, correlacionando-o com o Inventário Fatorial de Personalidade (IFP). Participaram 81 pessoas do interior de São Paulo, sendo $78 \%$ mulheres, inscritos em um programa de orientação profissional oferecido por uma universidade. Embora os dados obtidos tenham sido apenas preliminares, sendo o grupo muito pequeno para ser representativo para o propósito de investigação da validade de cons- 
truto, como os próprios autores alertam, os resultados indicaram evidências favoráveis à precisão e validade da versão brasileira do SDS, parecendo possuir propriedades psicométricas semelhantes ao original americano. Por exemplo, os coeficientes alfa de consistência interna do SDS (versão brasileira) variaram de 0,86 a 0,93 , muito próximos aos resultados americanos, que variaram de 0,91 a 0,93 .

Analisando os dados, percebeu-se que algumas correlações entre os traços de personalidade do IFP com os tipos de Holand atingiram significância estatística ( $\mathrm{p}<0,05)$. Entre eles, o tipo Realista de Holland com o traço Heterossexualidade do IFP, os tipos Social e Artístico de Holland com Assistência e Desejabilidade do IFP, simultaneamente, além de Agressividade e Desejabilidade para Social e Deferência e Afiliação para Artístico, isoladamente. Investigou-se também a correlação significativa entre o tipo Empreendedor, proposto pelo SDS, com os traços do IFP Dominância, Desempenho, Exibição, Agressão, Autonomia, Heterossexualidade e Ordem, além da correlação entre o tipo Convencional e o traço Persistência.

Ainda sobre as relações entre interesses e personalidade, o manual técnico do 16PF relata um estudo em que se buscou analisar a capacidade preditiva do $16 \mathrm{PF}$ no âmbito profissional, segundo a classificação tipológica proposta no SDS (Conn \& Rieke, 1994). Os resultados indicaram que as escalas de fator primário do $16 \mathrm{PF}$ prediziam os tipos de Holland. O estudo mostrou que as relações entre as escalas do $16 \mathrm{PF}$ e interesses vocacionais são substanciais, podendo ser usadas para enriquecer as interpretações acerca da Tipologia de Holland. Na discussão, inclusive, são apresentados os traços de personalidade de cada um dos tipos do modelo RIASEC, baseados nas descrições que as escalas do 16PF oferecem. Essa descrição é baseada nas análises estatísticas empregadas no tratamento dos dados do estudo.

Realçando a necessidade e importância das pesquisas com instrumentos de avaliação psicológica no contexto específico da OP, tendo o acréscimo de outros construtos além dos interesses, vale destacar alguns estudos nacionais e estrangeiros. Dentre eles, destaca-se o estudo de Primi e cols. (2000), que construíram um Inventário de Levantamento das Dificuldades de Escolha Profissional, o IDDP, aplicando-o em estudantes da $8^{a}$ série do ensino fundamental e de $2^{\mathrm{a}}$ e $3^{\mathrm{a}}$ séries do ensino médio, de escolas públicas e particulares, do interior de São Paulo.

Os autores concluíram que o instrumento satisfez o propósito de inventariar de maneira abrangente as dificuldades apontadas no modelo de Gati, Krausz e Osipow (1996), por meio de três fatores, a saber, a percepção da falta de informação e insegurança (Fator 1), um aspecto relacionado à motivação da escolha (Fator 2) e a falta de preparo para a escolha (Fator 3). Além disso, verificou-se que o IDDP distingue sistematicamente idades e tipos de escolas, mostrando-se um importante instrumento de diagnóstico para profissionais e pesquisadores da área de orientação profissional.

Em outro estudo nacional, com vistas a verificar a validade de construto do Inventário de Levantamento das Dificuldades da Decisão Profissional (IDDP), Primi, Noronha, Nunes e Ambiel (2006), realizaram um estudo correlacionando-o com o Inventário Fatorial de Personalidade (IFP) e a Bateria Fatorial CEPA, buscando verificar relações entre habilidades cognitivas, características de personalidade e dificuldade de decisão profissional. Os resultados indicaram que sujeitos com escores mais altos em inteligência fluida (Gf) mostraram tendência para liderança e persistência e pouca tendência para se apresentar como os outros gostariam que eles fossem, exatamente ao contrário daqueles que apresentaram escores mais altos em inteligência cristalizada $(\mathrm{Gc})$, indicando que parece existir uma tendência a maior autonomia intelectual e abertura em pessoas com Gf alta e maior dependência da opinião dos outros e maior aderência e tradicionalismo entre pessoas com Gc alto. Essa análise é reforçada também pelo fato de que o IDDP indicou que pessoas com Gf alto têm menos conflitos com pessoas significativas quanto à escolha do que aquelas com Gc mais alto. Nesse sentido, pode-se hipotetizar que uma maior dependência facilitaria o início de conflitos com pessoas significativas.

Entre os estudos estrangeiros, a correlação entre personalidade e escolha profissional também foi objeto de estudo. Pérez, Cupani e Beltramino (2004), na Argentina, objetivaram adaptar o Inventário de Personalidade 16PF-IPIP ao contexto de orientação profissional. Inicialmente fizeram a tradução do instrumento, do inglês para o espanhol, sendo que sua aplicação em amostra bilíngüe demonstrou boa consitência interna.

Ao avaliar a validade de critério do instrumento, os autores procuraram insvestigar a utilidade preditiva de algumas escalas primárias do 16PF-IPIP para escolha de carreira. Neste estudo, tal instrumento foi aplicado em 240 adolescentes argentinos com média de idade em 17 anos e, após três meses, ao término do ano letivo, o Cuestionario de Intenciones de Eléccion de Carrera (CIEC) foi administrado aos mesmos sujeitos. A partir da correlação dos escores, foi possível afirmar 
que algumas escalas do inventário de personalidade mostraram moderada utilidade preditiva para a orientação profissional, especialmente as escalas Sensibilidade e Complexidade, facetas, respectivamente, dos fatores Amabilidade e Cultura.

Tendo em vista o exposto e a necessidade de pesquisas com instrumentos de OP, no presente estudo objetivou-se explorar as correlações entre os itens da Escala de Aconselhamento Profissional (EAP) com os itens da Escala Atividades do SDS, a fim de se avaliar a validade de construto da EAP.

\section{MÉTODO}

\section{Participantes}

A amostra foi formada por 122 estudantes universitários dos cursos de Educação Artística (47,5\%), Psicologia $(34,4)$ e Medicina Veterinária $(18 \%)$, de duas instituições particulares de ensino superior do interior do Estado de São Paulo, sendo $81,1 \%$ do sexo feminino, com média de idade de 28,62 e desviopadrão de 10,34. As idades variaram de 17 a 73 anos.

\section{INSTRUMENTOS}

\section{SDS Forma $E$}

Consiste num instrumento composto por quatro escalas (Atividades, Competências, Carreiras e Habilidades) divididas em 6 subescalas, cada uma referente a um dos Tipos de Holland. Este instrumento é autoaplicável, facilmente interpretado pelo próprio sujeito e conta com estudos de adaptação ao contexto brasileiro.

Mansão (2005) buscou estimar sua precisão e demonstrou que o mesmo apresenta boa consistência interna e estabilidade temporal. Ao lado disso, a validade de constructo e critério também foram demonstradas por meio de análise fatorial e de comparação com outros instrumentos. Os dados obtidos nesta pesquisa demonstraram que a tipologia proposta pelo SDS é capaz de avaliar os interesses profissionais na população brasileira de maneira confiável.

\section{Escala de Aconselhamento Profissional}

A EAP foi desenvolvida por Noronha, Sisto e Santos (2007). Em um primeiro momento foram construídos 220 itens a partir das descrições de 65 profissões, tomando-se como referência diferentes guias profissionais, assim como descrições dos perfis fornecidos por universidades brasileiras, disponibilizados na internet.

Após essa etapa, procedeu-se à análise heurística dos itens pelos autores do instrumento, que separaram os itens presentes em mais de uma profissão. O critério para a manutenção do item foi a repetição dele em várias profissões. Feito isso, houve o cuidado de verificar se todas as áreas profissionais estavam representadas. Com esta redução chegou-se a uma escala de 61 itens, que mais representavam várias possibilidades profissionais e atendiam, de uma maneira geral, todas as áreas. Desta forma, pretendeu-se abranger uma gama ampla de atividades. O formato da escala é Likert, cujas respostas devem variar de freqüentemente (5) a nunca (1), de acordo com o interesse do avaliando em desenvolver cada atividade.

\section{RESULTADOS E DISCUSSÃO}

A Tabela 1 mostra as médias e desvios-padrão de cada tipo do SDS e da EAP. Pode-se perceber que os estudantes de Educação Artística apresentaram médias mais elevadas nos tipos Artístico e Social; os de Psicologia, nos tipos Social e Investigativo e de Veterinária, nos tipos Empreendedor e Investigativo. Na média geral, os tipos Social e Artístico foram predominantes. No que toca à EAP, Veterinária obteve a maior média, inclusive se comparada à média geral. 
TABELA 1

Estatísticas Descritivas Gerais e por Cursos

\begin{tabular}{lrrrrrrrr}
\hline & \multicolumn{2}{c}{ Educação Artística } & \multicolumn{2}{c}{ Psicologia } & \multicolumn{2}{c}{ Veterinária } & \multicolumn{2}{c}{ Geral } \\
\cline { 2 - 9 } & Média & DP & Média & DP & Média & DP & Média & DP \\
\hline SDS - R & 3,57 & 2,37 & 2,31 & 1,92 & 2,95 & 2,23 & 3,02 & 2,25 \\
SDS-I & 4,33 & 2,94 & 6,33 & 2,25 & 6,32 & 2,36 & 5,37 & 2,79 \\
SDS - A & 8,85 & 2,03 & 6,00 & 3,01 & 4,86 & 3,37 & 7,15 & 3,13 \\
SDS - S & 8,78 & 2,24 & 9,40 & 1,45 & 6,27 & 3,04 & 8,54 & 2,43 \\
SDS - E & 5,64 & 2,79 & 5,47 & 2,26 & 6,86 & 2,53 & 5,80 & 2,60 \\
SDS - C & 2,21 & 2,95 & 2,31 & 2,71 & 2,32 & 3,07 & 2,26 & 2,87 \\
EAP & 151,67 & 47,14 & 139,59 & 31,08 & 157,84 & 22,84 & 147,89 & 39,81 \\
\hline
\end{tabular}

A fim de se analisar se houve diferença significativa entre os cursos, foram realizadas ANOVAS. Para a EAP, as diferenças não foram significativas. Em relação ao SDS conclui-se que as diferenças entre os tipos $\mathrm{R} \quad[\mathrm{F}(3,122)=4,00 ; p=0,021], \mathrm{I} \quad[\mathrm{F}(3,122)=8,85$; $p<0,001]$, A $[\mathrm{F}(3,122)=23,71 ; p<0,001]$ e $\mathrm{S}[\mathrm{F}(3$, $122)=15,51 ; p<0,001]$ mostraram-se significativos.

Os itens da Escala Atividades Profissionais foram correlacionados com os tipos preconizados pelo SDS e nesse sentido, as correlações mais relevantes são discutidas a seguir. Para o tipo Realista, dentre as várias correlações significativas encontradas, o maior índice foi o item 56 (Promover a instalação de hotéis) $(\mathrm{r}=0,30)$, que parece evocar a visão econômica do sujeito Realista e suas características técnicas e de engenharia, caso leve-se em conta as várias possibili- dades que essa instalação pode sugerir, desde definir local economicamente mais viável para se implantar um hotel até as características das instalações do estabelecimento (Mansão, 2005). Já os itens 10 (Realizar turismo ecológico, $\mathrm{r}=0,29$ ) e 14 , (Reduzir o impacto de atividades industriais, urbanas e rurais no meio ambiente, $r=0,25$ ), evidenciam uma outra característica do Realista, que é a preferência por atividades agrícolas e de contato com a natureza. O item 44 (Produzir equipamentos de captação de energia solar, elétrica e nuclear, $r=0,26)$ retoma a vocação técnica e de engenharia do indivíduo pertencente a esse tipo. A Tabela 2 mostra as correlações entre a EAP e o tipo Realista (Mansão, 2005; Osborn, 2002; Holland \& Powell, 1994).

TABELA 2

Correlação entre Tipo Realista e Itens da EAP

\begin{tabular}{ccccccccc}
\hline itens & $\mathrm{r}$ & $\mathrm{p}$ & itens & $\mathrm{r}$ & $\mathrm{p}$ & itens & \multicolumn{1}{c}{$\mathrm{r}$} & $\mathrm{p}$ \\
\hline 1 & 0,07 & 0,443 & 22 & $-0,08$ & 0,399 & 43 & 0,15 & 0,090 \\
2 & 0,15 & 0,094 & 23 & 0,01 & 0,908 & 44 & $0,26^{* *}$ & 0,003 \\
3 & 0,09 & 0,325 & 24 & 0,08 & 0,412 & 45 & $0,22^{*}$ & 0,013 \\
4 & 0,08 & 0,400 & 25 & 0,08 & 0,366 & 46 & $0,19^{*}$ & 0,035 \\
5 & 0,09 & 0,308 & 26 & 0,16 & 0,071 & 47 & 0,00 & 0,993 \\
6 & 0,14 & 0,121 & 27 & 0,07 & 0,461 & 48 & 0,13 & 0,159 \\
7 & $0,21^{*}$ & 0,023 & 28 & 0,14 & 0,126 & 49 & 0,17 & 0,067 \\
8 & 0,16 & 0,079 & 29 & 0,04 & 0,653 & 50 & $-0,08$ & 0,372 \\
9 & $0,22^{*}$ & 0,017 & 30 & $0,19^{*}$ & 0,035 & 51 & $-0,04$ & 0,632 \\
& & & & & & & & cont.
\end{tabular}




$\begin{array}{rrrrrrrrr}10 & 0,29^{* *} & 0,001 & 31 & 0,05 & 0,579 & 52 & 0,06 & 0,526 \\ 11 & 0,16 & 0,069 & 32 & 0,19^{*} & 0,036 & 53 & 0,18^{*} & 0,041 \\ 12 & -0,02 & 0,859 & 33 & 0,12 & 0,196 & 54 & 0,12 & 0,171 \\ 13 & 0,03 & 0,770 & 34 & 0,12 & 0,178 & 55 & 0,04 & 0,653 \\ 14 & 0,25^{* *} & 0,005 & 35 & 0,22^{*} & 0,013 & 56 & 0,30^{* *} & 0,001 \\ 15 & 0,22^{*} & 0,016 & 36 & -0,02 & 0,854 & 57 & 0,01 & 0,908 \\ 16 & -0,01 & 0,870 & 37 & 0,07 & 0,462 & 58 & 0,12 & 0,168 \\ 17 & 0,01 & 0,930 & 38 & 0,14 & 0,131 & 59 & 0,02 & 0,801 \\ 18 & -0,04 & 0,657 & 39 & 0,16 & 0,067 & 60 & 0,04 & 0,622 \\ 19 & -0,01 & 0,879 & 40 & 0-, 11 & 0,222 & 61 & -0,03 & 0,691 \\ 20 & 0,07 & 0,446 & 41 & 0,14 & 0,125 & & & \\ 21 & -0,05 & 0,553 & 42 & 0,19^{*} & 0,031 & & & \end{array}$

${ }^{*}$ Correlações significativas ao nível de 0,05

** Correlações significativas ao nível de 0,001

Atividades voltadas aos cuidados com seres humanos foram as que se destacaram nas correlações com o tipo Investigativo, como pode ser visto na Tabela 3. Os itens 25, (Prevenir lesões e reabilitar sujeitos machucados), 36 (Dar atendimento ambulatorial em empresas) e 51 (Auxiliar no tratamento de pacientes com derrame cerebral, paralisia, traumatismo, dentre outros) foram os que apresentaram os maiores índices, a saber, $0,29,0,28$ e 0,26 , respectivamente. Tendo o tipo I características científicas, inclusive das ciências biológicas, e levando em conta as diferenças encontradas na ANOVA, pode-se perceber que os estudantes dos cursos da área de saúde optaram mais por atividades típicas. Além disso, os itens que se mostraram significativos e que se correlacionaram negativamente, quais sejam, o 55 (Desenhar, $\mathrm{r}=-0,32$ ) e o 43 (Recuperar obras e objetos de arte, $\mathrm{r}=-0,26)$, indicam atividades com características artísticas.

Além disso, nos itens 17 (Investigar a natureza e a causa das doenças), 18 (Realizar cirurgias), 12 (Orientar a população sobre prevenção de doenças) e 11 (Prevenir doenças em lavouras e rebanhos), encontram-se também correlações significativas. Percebe-se que esses itens evidenciam atividades típicas de profissionais de saúde e, mais especificamente, de saúde animal, vindo ao encontro das atividades que os estudantes de Medicina Veterinária que compuseram a amostra do estudo exercerão em seu futuro profissional.

TABELA 3

Correlação entre Tipo Investigativo e Itens da EAP

\begin{tabular}{ccccccccc}
\hline itens & $\mathrm{r}$ & $\mathrm{p}$ & itens & $\mathrm{R}$ & $\mathrm{p}$ & itens & $\mathrm{r}$ & $\mathrm{p}$ \\
\hline 1 & 0,11 & 0,235 & 22 & 0,01 & 0,921 & 43 & $-0,26^{* *}$ & 0,004 \\
2 & 0,05 & 0,549 & 23 & 0,05 & 0,556 & 44 & 0,08 & 0,362 \\
3 & 0,01 & 0,875 & 24 & $-0,15$ & 0,091 & 45 & $-0,04$ & 0,613 \\
4 & $-0,09$ & 0,343 & 25 & $-029^{* *}$ & 0,001 & 46 & 0,02 & 0,853 \\
5 & 0,04 & 0,619 & 26 & $-0,05$ & 0,567 & 47 & $0,20^{*}$ & 0,024 \\
6 & $-0,09$ & 0,335 & 27 & 0,16 & 0,072 & 48 & $-0,00$ & 0,969 \\
7 & $-0,22^{*}$ & 0,015 & 28 & $-0,09$ & 0,328 & 49 & $-0,03$ & 0,709 \\
& & & & & & & & \\
\end{tabular}




\begin{tabular}{cccccccrc}
8 & $-0,20^{*}$ & 0,025 & 29 & 0,02 & 0,826 & 50 & 0,14 & 0,122 \\
9 & 0,08 & 0,355 & 30 & 0,04 & 0,617 & 51 & $0,26^{* *}$ & 0,003 \\
10 & 0,07 & 0,454 & 31 & 0,11 & 0,227 & 52 & 0,14 & 0,114 \\
11 & $0,19^{*}$ & 0,034 & 32 & 0,00 & 0,951 & 53 & $-0,11$ & 0,234 \\
12 & $0,23^{*}$ & 0,010 & 33 & 0,06 & 0,534 & 54 & $-0,05$ & 0,546 \\
13 & 0,08 & 0,399 & 34 & $-0,06$ & 0,521 & 55 & $-0,32^{* *}$ & 0,000 \\
14 & 0,06 & 0,488 & 35 & $-0,06$ & 0,480 & 56 & $-0,10$ & 0,264 \\
15 & 0,11 & 0,225 & 36 & $0,28^{* *}$ & 0,002 & 57 & 0,02 & 0,774 \\
16 & 0,15 & 0,102 & 37 & $0,19^{*}$ & 0,035 & 58 & $-0,19^{*}$ & 0,037 \\
17 & $0,27^{* *}$ & 0,003 & 38 & $-0,02$ & 0,847 & 59 & $-0,09$ & 0,297 \\
18 & $0,24^{* *}$ & 0,007 & 39 & $-0,05$ & 0,597 & 60 & 0,10 & 0,287 \\
19 & 0,03 & 0,706 & 40 & $0,18^{*}$ & 0,045 & 61 & 0,04 & 0,675 \\
20 & 0,01 & 0,913 & 41 & 0,09 & 0,302 & & & \\
21 & $-0,02$ & 0,816 & 42 & $-0,05$ & 0,580 & & & \\
\hline
\end{tabular}

${ }^{*}$ Correlações significativas ao nível de 0,05

** Correlações significativas ao nível de 0,001

A análise dos dados referentes ao tipo Artístico trouxe à luz vários pontos interessantes. Seis itens da EAP se correlacionaram positivamente com a escala de atividades do SDS, com coeficientes superiores a 0,40 , como se observa na Tabela 4 . Os itens 43 (Recuperar obras e objetos de arte), 6 (Coordenar a apresentação de um espetáculo de dança) e 55 (Desenhar) foram os que apresentaram os maiores índices de correlação ( $r=0,48,0,42$ e 0,42 , respectivamente).
Além desses itens, outros mostraram correlações negativas, cujos coeficientes de correlação mais altos foram 18 (Realizar cirurgia), 51 (Auxiliar no tratamento de pacientes com derrame cerebral, paralisias, traumatismos, dentre outros), 17 (Investigar a natureza e a causa das doenças) e 50 (Analisar o metabolismo de animais e vegetais). Interessante o fato de que os itens com correlação negativa tratam de atividades relacionadas à área de saúde, com características rotineiras e pouco criativas, contrárias às características comuns ao tipo Artístico (Osborn, 2002).

TABELA 4

Correlação entre Tipo Artístico e Itens da EAP

\begin{tabular}{ccccccccc}
\hline itens & $\mathrm{R}$ & $\mathrm{p}$ & itens & \multicolumn{1}{c}{$\mathrm{R}$} & $\mathrm{p}$ & itens & \multicolumn{1}{c}{$\mathrm{r}$} & \multicolumn{1}{c}{$\mathrm{p}$} \\
\hline 1 & $-0,12$ & 0,177 & 22 & $-0,04$ & 0,629 & 43 & $0,48^{* *}$ & 0,000 \\
2 & 0,10 & 0,279 & 23 & 0,07 & 0,441 & 44 & 0,12 & 0,169 \\
3 & $-0,10$ & 0,247 & 24 & $0,41^{* *}$ & 0,000 & 45 & $0,39^{* *}$ & 0,000 \\
4 & 0,01 & 0,860 & 25 & $-0,09$ & 0,321 & 46 & 0,12 & 0,174 \\
5 & $0,32^{* *}$ & 0,000 & 26 & $0,39^{* *}$ & 0,000 & 47 & $-0,08$ & 0,398 \\
6 & $0,42^{* *}$ & 0,000 & 27 & 0,16 & 0,072 & 48 & 0,01 & 0,890 \\
7 & $0,41^{* *}$ & 0,000 & 28 & $0,37^{* *}$ & 0,000 & 49 & 0,05 & 0,577 \\
8 & $0,41^{* *}$ & 0,000 & 29 & 0,17 & 0,055 & 50 & $-0,25^{* *}$ & 0,005 \\
& & & & & & & & cont.
\end{tabular}




\begin{tabular}{ccccccccc}
9 & 0,12 & 0,199 & 30 & 0,10 & 0,248 & 51 & $-0,29^{* *}$ & 0,001 \\
10 & 0,40 & 0,674 & 31 & $-0,02$ & 0,793 & 52 & $0,21^{*}$ & 0,016 \\
11 & $-0,01$ & 0,880 & 32 & 0,14 & 0,131 & 53 & $0,21^{*}$ & 0,021 \\
12 & $-0,02$ & 0,806 & 33 & $0,19^{*}$ & 0,030 & 54 & $0,24^{* *}$ & 0,008 \\
13 & $-0,01$ & 0,875 & 34 & $0,18^{*}$ & 0,049 & 55 & $0,42^{* *}$ & 0,000 \\
14 & 0,02 & 0,793 & 35 & $0,38^{* *}$ & 0,000 & 56 & $0,27^{* *}$ & 0,003 \\
15 & $-0,04$ & 0,630 & 36 & $-0,08$ & 0,377 & 57 & $0,25^{* *}$ & 0,004 \\
16 & $-0,01$ & 0,915 & 37 & $-0,06$ & 0,469 & 58 & $0,41^{* *}$ & 0,000 \\
17 & $-0,25^{* *}$ & 0,004 & 38 & 0,10 & 0,258 & 59 & $0,30^{* *}$ & 0,001 \\
18 & $-0,32^{* *}$ & 0,000 & 39 & 0,13 & 0,131 & 60 & 0,08 & 0,392 \\
19 & $-0,12$ & 0,198 & 40 & $-0,18^{*}$ & 0,046 & 61 & 0,03 & 0,741 \\
20 & $-0,08$ & 0,394 & 41 & 0,06 & 0,491 & & & \\
21 & 0,03 & 0,769 & 42 & $0,18^{*}$ & 0,043 & & & \\
\hline
\end{tabular}

* Correlações significativas ao nível de 0,05

** Correlações significativas ao nível de 0,001

Quanto ao tipo Social, notou-se que os itens da EAP que se correlacionaram mais positivamente às atividades propostas pelo SDS estavam mais relacionados ao estudo da origem e evolução da história e cultura humana e ao contato com a arte, porém em funções de coordenação de pessoal, e não em atividades artísticas puras, criativas e/ou centradas. A Tabela 5 mostra que os itens 52 (Estudar o passado humano em seus múltiplos aspectos) e 5 (Estudar a origem do homem e da cultura), mostraram inclinação para atividades em que se possa lidar com problemas sociais e éticos e que lhes dê ferramentas para pensar sobre a situação atual da humanidade, tendendo a profissões como Antropologia, Sociologia e mesmo Psicologia (Holland \& Powell, 1994; Mansão, 2005).
Já os itens 24 (Responsabilizar-se pela direção teatral) e 8 (Ensaiar artista para um espetáculo) evidenciam atividades que, embora tenham um cunho artístico, exigem do profissional um contato constante com pessoas e habilidades sociais como falar em público e de organização, além da habilidade artística. Ainda, o item 57 (Escrever e revisar textos) parece evidenciar uma caraterística voltada à área educacional, bastante importante dentro do tipo Social (Conn \& Rieke, 1994). Além desses, os itens 18 (Realizar cirurgias) e o item 50 (Analisar o metabolismo de seres animais e vegetais) mostraram-se com correlações altas negativas.

\section{TABELA 5}

Correlação entre Tipo Social e Itens da EAP

\begin{tabular}{ccccccccc}
\hline itens & $\mathrm{R}$ & $\mathrm{p}$ & itens & $\mathrm{R}$ & $\mathrm{p}$ & itens & $\mathrm{r}$ & \multicolumn{1}{c}{$\mathrm{p}$} \\
\hline 1 & $-0,16$ & 0,082 & 22 & 0,13 & 0,145 & 43 & 0,18 & 0,051 \\
2 & $-0,08$ & 0,347 & 23 & 0,11 & 0,206 & 44 & $-0,17$ & 0,055 \\
3 & $-0,18^{*}$ & 0,043 & 24 & $0,29^{* *}$ & 0,001 & 45 & 0,13 & 0,139 \\
4 & $-0,16$ & 0,081 & 25 & 0,00 & 0,928 & 46 & $-0,21^{*}$ & 0,017 \\
5 & $0,28^{* *}$ & 0,002 & 26 & 0,16 & 0,076 & 47 & 0,08 & 0,399 \\
6 & $0,26^{* *}$ & 0,003 & 27 & $-0,06$ & 0,536 & 48 & $-0,22^{*}$ & 0,014 \\
& & & & & & & & \\
\end{tabular}




\begin{tabular}{ccccccccc}
7 & 0,13 & 0,145 & 28 & 0,15 & 0,099 & 49 & $-0,21^{*}$ & 0,017 \\
8 & $0,27^{* *}$ & 0,003 & 29 & 0,05 & 0,555 & 50 & $-0,24^{* *}$ & 0,007 \\
9 & 0,03 & 0,682 & 30 & $-0,09$ & 0,336 & 51 & $-0,04$ & 0,640 \\
10 & $-0,09$ & 0,315 & 31 & $-0,15$ & 0,102 & 52 & $0,29^{* *}$ & 0,001 \\
11 & $-0,19^{*}$ & 0,035 & 32 & 0,02 & 0,787 & 53 & $-0,01$ & 0,896 \\
12 & 0,00 & 0,967 & 33 & $-0,06$ & 0,471 & 54 & 0,03 & 0,699 \\
13 & $-0,11$ & 0,240 & 34 & 0,09 & 0,330 & 55 & 0,06 & 0,534 \\
14 & $-0,19^{*}$ & 0,033 & 35 & 0,04 & 0,637 & 56 & $-0,01$ & 0,917 \\
15 & $-0,08$ & 0,350 & 36 & 0,02 & 0,793 & 57 & $0,27^{* *}$ & 0,003 \\
16 & 0,14 & 0,110 & 37 & $-0,25^{* *}$ & 0,006 & 58 & 0,16 & 0,082 \\
17 & $-0,12$ & 0,176 & 38 & $-0,04$ & 0,665 & 59 & $0,26^{* *}$ & 0,004 \\
18 & $-0,37^{* *}$ & 0,000 & 39 & $-0,03$ & 0,710 & 60 & $-0,15$ & 0,086 \\
19 & $-0,23^{* *}$ & 0,009 & 40 & $-0,15$ & 0,088 & 61 & $0,26^{* *}$ & 0,004 \\
20 & $-0,21^{*}$ & 0,020 & 41 & $-0,09$ & 0,329 & & & \\
21 & 0,00 & 0,984 & 42 & $-0,08$ & 0,359 & & & \\
\hline
\end{tabular}

* Correlações significativas ao nível de 0,05

** Correlações significativas ao nível de 0,001

Nenhum dos itens da EAP se correlacionou negativamente com a Escala Atividades do SDS no tipo Empreendedor, entretanto, quatro apresentaram correlação positiva com coeficientes iguais ou superiores a 0,30 . Na tabela 6 , percebe-se que os itens 9 (Cuidar de princípios e normas relativos a arrecadação de impostos, taxas e obrigações tributárias) e 32 (Divulgar e vender softwares) tiveram as correlações mais altas. Interessante que, entre os itens com correlação significativa, esses são os que melhor descrevem atividades essencialmente empreendedoras, já que se referem a atividades que valorizam aspectos econômicos e exigem comportamentos verbais persuasivos e sociais, porém sem requerer atividades manuais, que exijam concentração continuada (Osborn, 2002).

Nos demais itens que se correlacionaram acima de 0,30, a saber, 21 (Conduzir relações entre empresa e empregado) e 42 (Projetar robôs e sistemas digitais para fábricas), as características empreendedoras já não são identificadas de forma tão clara quanto nos demais itens. No 21, embora o indivíduo tenha que usar de suas habilidades social e verbal, a posição que ocupa não é a de liderança, típica das personalidades empreendedoras, mas de intermediação (Mansão, 2005). Quanto ao outro item citado, a atividade descrita aparentemente é típica do Realista.

TABELA 6

Correlação entre Tipo Empreendedor e Itens da EAP

\begin{tabular}{ccccccccc}
\hline itens & $\mathrm{r}$ & $\mathrm{p}$ & itens & $\mathrm{R}$ & $\mathrm{p}$ & itens & $\mathrm{r}$ & $\mathrm{p}$ \\
\hline 1 & $0,26^{* *}$ & 0,004 & 22 & $0,26^{* *}$ & 0,004 & 43 & $-0,07$ & 0,440 \\
2 & 0,14 & 0,127 & 23 & $0,24^{* *}$ & 0,007 & 44 & 0,12 & 0,182 \\
3 & $0,25^{* *}$ & 0,005 & 24 & $0,23^{*}$ & 0,011 & 45 & 0,08 & 0,391 \\
4 & $0,23^{* *}$ & 0,010 & 25 & 0,11 & 0,208 & 46 & 0,17 & 0,058 \\
& & & & & & & & \\
\end{tabular}




\begin{tabular}{crrrrrrrr}
5 & 0,06 & 0,517 & 26 & 0,15 & 0,106 & 47 & $0,20^{*}$ & 0,029 \\
6 & $0,27^{* *}$ & 0,002 & 27 & 0,11 & 0,232 & 48 & 0,05 & 0,547 \\
7 & 0,10 & 0,271 & 28 & 0,11 & 0,204 & 49 & 0,16 & 0,070 \\
8 & $0,21^{*}$ & 0,022 & 29 & 0,09 & 0,307 & 50 & 0,04 & 0,663 \\
9 & $0,34^{* *}$ & 0,000 & 30 & $0,20^{*}$ & 0,031 & 51 & 0,03 & 0,702 \\
10 & $0,19^{*}$ & 0,033 & 31 & 0,13 & 0,165 & 52 & $-0,00$ & 0,955 \\
11 & $0,21^{*}$ & 0,015 & 32 & $0,34^{* *}$ & 0,000 & 53 & $0,22^{*}$ & 0,022 \\
12 & 0,09 & 0,302 & 33 & $0,28^{* *}$ & 0,002 & 54 & $0,21^{*}$ & 0,022 \\
13 & 0,15 & 0,088 & 34 & 0,14 & 0,112 & 55 & $-0,03$ & 0,720 \\
14 & 0,16 & 0,082 & 35 & 0,17 & 0,066 & 56 & $0,21^{*}$ & 0,018 \\
15 & $0,23^{* *}$ & 0,009 & 36 & 0,11 & 0,202 & 57 & $0,18^{*}$ & 0,043 \\
16 & $-0,02$ & 0,777 & 37 & 0,14 & 0,109 & 58 & 0,15 & 0,101 \\
17 & 0,01 & 0,910 & 38 & 0,08 & 0,398 & 59 & 0,10 & 0,274 \\
18 & $0,19^{*}$ & 0,031 & 39 & 0,16 & 0,072 & 60 & 0,12 & 0,200 \\
19 & 0,15 & 0,099 & 40 & 0,07 & 0,420 & 61 & 0,04 & 0,616 \\
20 & 0,13 & 0,136 & 41 & 0,15 & 0,091 & & & \\
21 & $0,33^{* *}$ & 0,000 & 42 & $0,30^{* *}$ & 0,001 & & & \\
\hline${ }^{*}$ Correlações significativas ao nivel de 0,05 & & & & & \\
${ }^{*}$ Correlações significativas ao nível de 0,001 & & & & &
\end{tabular}

Tendo em vista as correlações entre a EAP e o tipo Convencional, apresentadas na Tabela 10, os itens 9 (Cuidar de princípios e normas relativos a arrecadação de impostos, taxas e obrigações tributárias) e 47 (Analisar e interpretar dados numéricos) se destacam nesse sentido, evidenciando a principal característica do tipo Convencional, que é a importância dada ao fator econômico em atividades passivas e bem organizadas, que não exijam esforços criativos, intelectuais e sociais (Holland \& Powell, 1994). Ao lado disso, o item 4 (Coordenar as operações fiscais e financeiras de empresas) embora também exponha a característica matemático-financeira de forma bastante clara, não parece ser condizente com as preferências de atuação do Convencional, já que os sujeitos desse tipo preferem atuar como subordinados, evitando situações que exijam originalidade e espontaneidade, típicas dos chefes e coordenadores (Osborn, 2002).

TABELA 7

Correlação entre Tipo Convencional e Itens da EAP

\begin{tabular}{ccccccccc}
\hline itens & $r$ & $p$ & itens & $r$ & $p$ & itens & $r$ & $p$ \\
\hline 1 & $0,18^{*}$ & 0,046 & 22 & 0,12 & 0,176 & 43 & $-0,08$ & 0,372 \\
2 & 0,01 & 0,888 & 23 & $0,19^{*}$ & 0,035 & 44 & 0,02 & 0,846 \\
3 & 0,15 & 0,099 & 24 & $-0,13$ & 0,153 & 45 & $-0,02$ & 0,828 \\
4 & $0,25^{* *}$ & 0,006 & 25 & $0,18^{*}$ & 0,044 & 46 & $-0,05$ & 0,610 \\
5 & 0,00 & 0,981 & 26 & $-0,02$ & 0,823 & 47 & $0,29^{* *}$ & 0,001 \\
6 & 0,03 & 0,765 & 27 & $-0,05$ & 0,591 & 48 & 0,05 & 0,548 \\
7 & $-0,01$ & 0,924 & 28 & $-0,07$ & 0,431 & 49 & 0,04 & 0,616 \\
& & & & & & & & cont.
\end{tabular}




\begin{tabular}{ccccccccc}
8 & $-0,01$ & 0,867 & 29 & 0,04 & 0,671 & 50 & $-0,06$ & 0,530 \\
9 & $0,32^{* *}$ & 0,000 & 30 & 0,10 & 0,277 & 51 & 0,04 & 0,683 \\
10 & 0,08 & 0,390 & 31 & $-0,03$ & 0,715 & 52 & $-0,01$ & 0,871 \\
11 & 0,10 & 0,282 & 32 & 0,13 & 0,141 & 53 & 0,11 & 0,230 \\
12 & 0,02 & 0,811 & 33 & $-0,03$ & 0,715 & 54 & 0,12 & 0,187 \\
13 & 0,04 & 0,652 & 34 & 0,02 & 0,785 & 55 & $-0,10$ & 0,252 \\
14 & 0,02 & 0,844 & 35 & $-0,04$ & 0,618 & 56 & 0,09 & 0,319 \\
15 & 0,08 & 0,376 & 36 & $-0,02$ & 0,774 & 57 & $-0,09$ & 0,334 \\
16 & $-0,07$ & 0,442 & 37 & 0,00 & 0,962 & 58 & 0,02 & 0,838 \\
17 & 0,02 & 0,843 & 38 & $-0,05$ & 0,553 & 59 & 0,09 & 0,292 \\
18 & $-0,05$ & 0,601 & 39 & $-0,01$ & 0,899 & 60 & $-0,04$ & 0,663 \\
19 & $-0,18^{*}$ & 0,046 & 40 & $-0,05$ & 0,591 & 61 & $-0,07$ & 0,458 \\
20 & $-0,13$ & 0,165 & 41 & 0,11 & 0,239 & & & \\
21 & 0,06 & 0,481 & 42 & 0,01 & 0,867 & & & \\
\hline
\end{tabular}

* Correlações significativas ao nível de 0,05

** Correlações significativas ao nível de 0,001

\section{CONSIDERAÇÕES FINAIS}

A atividade profissional parece assumir na atualidade uma das mais importantes tarefas a se cumprir, mas ainda é visível a pouca importância dada à orientação profissional no contexto nacional, haja vista os poucos estudos realizados e instrumentos disponíveis para a avaliação dos interesses disponíveis e no Brasil.

Assim, é importante que se debruce sobre os instrumentos já existentes a fim de atualizá-los e adaptálos e que se estude cada vez mais formas eficazes e confiáveis de se promover a escolha profissional. Ao lado disso, é importante que se produzam dados empíricos com as amostras profissionais/profissionalizantes brasileiras a fim de que se conheça melhor seus interesses e assim, seja possível promover um melhor ajustamento entre as pessoas, suas expectativas e interesses profissionais.

O presente estudo não teve a pretensão de esgotar as possibilidades de estudo, muito há que se investigar no que respeita à $\mathrm{OP}$ e, mais especificamente, aos instrumentos de medida de interesses. No entanto, acredita-se que os objetivos dessa pesquisa foram alcançados, à medida que permitiu refletir sobre dois testes psicológicos, a partir de uma amostra com representantes de cursos profissionais distintos.

Além disso, ao se discutir a coerência teórica das correlações observadas, pode-se dizer que a EAP, nessa amostra, mostrou possuir evidências de validade de construto, uma vez que parece avaliar os interesses por atividades profissionais de forma coerente com o SDS, embora se tenha clareza das diferenças teóricas que embasam cada um dos instrumentos. Convém, ainda, destacar que pesquisas que relacionem instrumentos e construtos psicológicos são necessárias, uma vez que no bojo do processo de avaliação psicológica, a informação dada por testes distintos tende a colaborar com a compreensão das características dos sujeitos avaliados.

\section{REFERÊNCIAS}

Anastasi, A., \& Urbina, S. (2000). Testagem psicológica. Porto Alegre: Artmed.

Conn, S. R., \& Rieke, M. L. (1994). The 16PF fifth edition technical manual. Champaign, IL: Institute for Personality and Ability Testing.

Conselho Federal de Psicologia (2001). Resolução $n^{o}$ 25/2001. Retirado em 15 de agosto de 2005, de http://www.pol.org.br

Conselho Federal de Psicologia (2003). Resolução $n^{\circ}$ 02/2003. Retirado em 02 de novembro de 2005, de http://www.pol. org.br.

Fryer, D. H. (1931). The measurement of interests. New York: Holt.

Gati, I., Krausz, M., \& Osipow, S. H. (1996). A taxonomy of difficulties in career decision making. Journal of Counseling Psychology, 43(4), 510-526. 
Holland, J. L., Frietsche, B. A., \& Powell, A. B. (1994). SDS SelfDirected Search Technical Manual. Florida: Psychological Assesment Resources, Inc.

Holland, J. L., \& Powell, A. B. (1994). SDS Career Explorer: Exploring you rfuture with the SDS. Florida: Psychological Assesment Resources, Inc.

Leitão, L. M., \& Miguel, J. P. (2004). Avaliação dos interesses. Em L. M. Leitão (Org.), Avaliação psicológica em orientação escolar e profissional (pp. 179-262). Coimbra: Quarteto.

Lent, R. W., Hackett, G., \& Brown, S. D. (1994). Toward a unifying social cognitive theory of career and academic interest, choice, and performance. Journal of Vocational Behavior, 45, 79-122.

Mansão, C. S. M. (2005). Interesses profissionais:Validação do Self-Directed Search Career Explorer - SDS. Tese de doutorado não-publicada, Pontifícia Universidade Católica de Campinas, Campinas.

Noronha, A. P. P., Sisto, F. F., \& Santos, A. A. A. (2007). Escala de Atividades Profissionais - Manual técnico. São Paulo: Vetor.

Osborn, D. S. (2002). Using the Self-Directed Search Career Explorer with middle school students: The practicality of Holland's RIASEC. Trabalho apresentado na Careers Across America 2002: Best Practices \& Ideas in Career Development Conference Proceedings. Retirado em 22 de junho de 2005, de http://www.eric.ed.gov

Pérez, E., Cupani, M., \& Beltramino, C. (2004). Adaptación del Inventario de Personalidad 16PF-IPIP a un contexto de orientación: Estudio preliminar. Evaluar, 4, 23-49.
Primi, R., Hernandez-Munhoz, A. M., Bighetti, C. A., Di Nucci, E. P., Pellegrini, M. C. K., \& Moggi, M. A. (2000). Desenvolvimento de um inventário de levantamento das dificuldades da decisão profissional. Psicologia: Reflexão e Crítica, 13(3), 451-463.

Primi, R., Moggi, M. A., \& Casellato, E. O. (2004). Estudo correlacional do inventário de busca auto-dirigida (Self-directed Search) com o IFP. Psicologia Escolar e Educacional, 8(1), 47-54.

Primi, R., Noronha, A. P. P., Nunes, M. F. O., \& Ambiel, R. A. M. (2006). Estudo correlacional entre habilidades, personalidade e dificuldade de escolha profissional. Em C. Machado, L. Almeida, M. A. Guisande, M. Gonçalves \& V. Ramalho (Orgs.), XI Conferência Internacional: Avaliação Psicológica Formas e Contextos (pp. 421-434). Braga: Psiquílibrios.

Savickas, M. L. (1995). Examining the personal meaning of nventoried interests during career counseling. Journal of $\mathrm{Ca}$ reer Assessment, 3(2), 188-201.

Strong, E. K. (1943). Vocational interests of men and women. Stanford: Stanford University Press.

Recebido: 21/09/2006

Última revisão: 24/01/2008

Aceite final: 25/02/2008

\section{Sobre os autores:}

Ana Paula Porto Noronha: Doutora em Psicologia: Ciência e Profissão pela Pontifícia Universidade Católica de Campinas. Docente do Programa de Pós-gradução Stricto Sensu em Psicologia da Universidade São Francisco. Bolsista Produtividade em Pesquisa do CNPq.

Rodolfo Augusto Matteo Ambiel: Graduando em Psicologia pela Universidade São Francisco. Bolsista de Iniciação Cientíca PIBIC/CNPq. Endereço eletrônico: ambielram@yahoo.com.br 